\title{
RISCOS AMBIENTAIS EM UMA SONDA DE PERFURAÇÃO DE PETRÓLEO ONSHORE NA UNIDADE DE NEGÓCIOS-RN/CE- MOSSORÓ/RN
}

\author{
F. N. P. M. Aquino e L. F. L. G. Costa \\ Instituto Federal de Educação, Ciência e Tecnologia do Rio Grande do Norte - Campus Currais Novos \\ nixon.uab@hotmail.com - lucia.lucio@ifrn.edu.br
}

Artigo submetido em maio/2011 e aceito em junho/2011

\section{RESUMO}

O presente estudo buscou focar todo o processo de perfuração de uma sonda onshore, do qual, em toda a sua extensão proporciona riscos ambientais aos trabalhadores, apresentando um histórico desde quando iniciou esse trabalho com sondas, além de destacar as normas do Programa de Prevenção de Riscos Ambientais de acordo com as exigências do Ministério do Trabalho e Emprego, ressaltando a importância do uso de equipamentos de uso coletivo e individual. Foi feita uma pesquisa qualitativa na Unidade de Negócios Negócio (UN)RN/CE- MOSSORÓ/RN, onde foi possível identificar os acidentes ocorridos no primeiro semestre de 2010. A pesquisa finaliza com uma análise dos acidentes ocorridos, comparando-os com os lugares sucedidos e o setor que mais está exposto a acidente ambiental na sonda de perfuração. $O$ trabalho se conclui apresentando atos de extrema necessidade de se aplicar para se evitar um índice tão alto de acidentes neste tipo de atividade de extração de petróleo.

PALAVRAS-CHAVE: Petróleo, riscos ambientais, perfuração, sonda, mapa de riscos.

\section{AMBIENT RISKS IN ONE SOUNDING LEAD OF PERFORATION OF OIL ONSHORE IN THE UNIT OF NEGÓCIOS-RN/CE- MOSSORÓ/RN}

\begin{abstract}
This study sought to focus the entire process of drilling an onshore rig, which, in all its extension provides environmental risks to workers, presenting a historical background from when he started this work with probes, and highlight the rules of the Prevention Program Environmental Risks in accordance with the requirements of the Ministry of Labor, stressing the importance of using equipment for collective use and individual. Was used a qualitative research in the Unit

Business (UN) - RN/CE- MOSSORO / RN, where it was possible to identify the accidents during the first half of 2010. The research concludes with an analysis of accidents and comparing them with the places and successful industry that is exposed to more environmental accident in the drilling rig. The work concludes with acts of extreme need to implement to avoid an accident rate so high in this type of activity of oil extraction.
\end{abstract}

KEY-WORDS: petroleum, environmental risks, drilling rig, the risk maps. 


\section{RISCOS AMBIENTAIS EM UMA SONDA DE PERFURAÇÃO DE PETRÓLEO ONSHORE NA UNIDADE DE NEGÓCIOS-RN/CE- MOSSORÓ/RN}

\section{INTRODUÇÃO}

Há muito tempo que o homem utiliza o petróleo para atender as suas necessidades de consumo de energia. Desde que o Coronel Edwin Drake perfurou o primeiro poço de petróleo (1859Pensilvânia- USA), a indústria do petróleo cresceu muito, tornando o petróleo uma das principais fontes de energia do planeta.

A demanda mundial, entretanto, é de aproximadamente 80 milhões de barris diários. Segundo Appenzeller (2004), o Brasil consumiu em média 803 milhões de barris anuais em 2002, ficando abaixo de alguns países como a Rússia (985 milhões), China e Japão, com 1.935 milhões e EUA, com 7.191 milhões de barris anuais.

O petróleo é um óleo natural fóssil, ou seja, "Resto ou vestígio de planta ou animal que se apresenta petrificado ou endurecido em camadas rochosas de antigas eras geológicas" (LAROUSSE, 1992, p.527).

Esse óleo é decorrente de depósitos marítimos, ou seja, áreas de antigos mares e movimentações do leito marinho, cheias de material orgânico, que atingem profundidades ideais para manter pressão e temperaturas altas e formar o óleo. Além disso, pedras porosas, arenito, calcário e sais de rochas impedem sua liberação com facilidade, proporcionando, algumas vezes, suas migrações.

Ele é formado basicamente de hidrocarbonetos, essencialmente de carbono, mas também, são encontrados outros elementos como nitrogênio, enxofre e oxigênio. Sabe-se que o petróleo é a principal fonte de energia do mundo e junto com o gás natural (subproduto da indústria do petróleo) alimenta mais de $60 \%$ das necessidades energéticas das economias industriais.

Segundo a Energy InformationAdministration (2008), o maior produtor de petróleo, em 2006, foi a Arábia Saudita, com aproximadamente 10.800 milhões de barris por dia. O Brasil estava no 13으 lugar do ranking, com aproximadamente 2.163 milhões de barris por dia. Segundo a mesma fonte, o maior consumidor foi os EUA, com 20.588 milhões de barris por dia, ficando o Brasil no 8ㅇ lugar, com 2.183 milhões de barris por dia. Com a descoberta do Pré-sal onde sua estimativa de volume é no mínimo de 9,5 bilhões de barris, podendo chegar a 14 bilhões, o que praticamente dobra as atuais reservas, o Brasil tornará uma das cinco maiores potência petrolífera mundial.

As atividades que as indústrias petrolíferas desenvolvem são de fato as mais fantásticas atividades produtivas e organizadas em toda a existência do ser humano. Tendo diversos conhecimentos exigidos nesse contexto, que vai desde a ciência, passando pela tecnologia, engenharia finanças, englobando fatores sociais, ecológicos, e recursos humanos que são ferramentas essenciais para o sucesso dessa indústria. 
Tais atividades são consideras de alto risco devido ao grau de periculosidade que atividade está exposta. As sondas de perfuração de petróleo (onshore) foram escolhidas como objeto principal de estudo para composição desse trabalho, devido à existência de diversos tipos de riscos, denominadas de "riscos ambientais".

Esses riscos ambientais que podem advir da atividade de perfuração de um poço de petróleo podem ser identificados como os agentes físicos, químicos, biológicos, ergonômicos e de acidentes/mecânicos que possam trazer ou ocasionar danos à saúde do trabalhador nos ambientes de trabalho, em função de sua natureza, concentração, intensidade e tempo de exposição ao agente. Os danos também se estendem à fauna e flora devido à remoção da vegetação no local onde será perfurado o poço; erosão provocada pela destruição da vegetação; agressões ao meio ambiente causadas pelos resíduos dos fluidos de perfuração, fragmentos das rochas (cascalhos) perfuradas dispostos em diques de perfuração e/ou percolação de contaminantes para lençóis freáticos; e contaminação dos lençóis freáticos e aqüíferos subterrâneos, causada por perdas dos fluidos de perfuração para as formações geológicas durante a perfuração. De acordo com Goldbarg e Luna (2000), a definição do problema é uma das fases mais importantes do processo e compreende a clara percepção do desafio colocado.

Assim busca-se desenvolver um mapeamento dos tipos de riscos ambientais como identificador de prevenção de acidentes de uma sonda de perfuração de petróleo (onshore), tendo como base o programa de Segurança, Meio Ambiente e Saúde (SMS).

\section{ASPECTOS METODOLÓGICOS}

A utilização da sonda de perfuração é necessária para perfurar poços que permitam o acesso a reservatórios de petróleo ou gás natural, porém os riscos desencadeados por essa prática são inúmeros. Portanto como base nesta afirmação o trabalho tendo como referência o programa de Segurança, Meio Ambiente e Saúde (SMS) tem como foco de estudo "A sonda de perfuração de petróleo e seus riscos ambientais, para definir um mapeamento destes riscos evitando assim, tantos acidentes de trabalho.

Toda pesquisa necessita de estudos, assim, inicialmente foi obtido dados da Petrobrás (UNRN/CE- MOSSORÓ/RN), bem como, levantamento de informações em livros que abordam a área petrolífera e temas provenientes de artigos, seminários e cursos publicados por centros de pesquisa, empresas, universidades, órgãos governamentais e ONG's. O trabalho analisou a Legislação das Normas Regulamentadoras do Ministério do Trabalho e Emprego desde 1978, procurou-se estudar campos que se relacionam com o estudo da sonda de perfuração. Realizando um estudo teórico com José Eduardo Thomaz, Lima e trabalhos acadêmicos, do qual, fez uma grande contribuição com informações precisas e essenciais. O material selecionado foi analisado e dividido por assunto a ser descrito nos capítulos seguintes,

É preciso também destacar que foi realizada uma entrevista com o supervisor de Segurança, Meio ambiente e Saúde (SMS) da Petrobrás-UN-RN/CE-Mossoró/RN responsável da Unidade de Negócios, do qual, foi de suma importância para identificar acidentes ocorridos durante o primeiro 
semestre de 2010 nesta unidade. Na entrevista, obteve-se informações que compilou dados suficientes para gerar gráficos dos acidentes ocorridos em sondas de perfuração do qual a Petrobrás tem domínio, nesta Unidade de Negócios.

Após ter identificado o tipo de pesquisa, o objeto de estudo, ter levantado todo o material de pesquisa e definido todo o conteúdo pôde-se construir o mapeamentos da sonda de perfuração e definir os locais que mais geram riscos de acidentes ambientais, sejam eles: físicos, químicos, mecânicos, ergonômicos ou biológicos.

Os dados dos gráficos formulados com as informações obtidas na entrevista realizada com o Supervisor de SMS possibilitaram uma comparação com o mapeamento dos riscos ambientais da sonda de perfuração construído, essa comparação foi realizada com os acidentes sucedidos na Petrobrás-UN-RN/CE-Mossoró-RN por os seguintes setores: partes do corpo mais atingidas, os turnos e o tempo de experiência, onde se identificou os principais pontos de riscos e os setores que mais estão sujeitos a sofrer os acidentes.

\section{PERFURAÇÃO TERRESTRE (ONSHORE)}

Em uma sonda de perfuração as rochas são perfuradas pela ação de rotação e peso aplicados a uma broca existente na extremidade de uma coluna de perfuração. Ou seja, a perfuração é um conjunto de atividades e operações destinadas a projetar, programar e realizar a abertura de poços.

A construção de poços é uma das atividades mais importantes da indústria de petróleo, cabendo a engenharia de poços a tarefa de perfurar, testar e equipar os poços para que esses atendam aos requisitos de exploração ou produção.

Os mais antigos poços de petróleo foram perfurados pelo método percussivo (cabo e ferramenta perfurante), isto é, foram perfurados simplesmente percutindo o solo.

Este método logo se tornou limitado, pois, não atingiam grandes profundidades. Devido a esta limitação, a partir da década de 1930 foi introduzido o método de perfuração giratória, no qual a broca poderia atingir profundidades bem maiores (12.000 metros $=38.000$ pés).

As sondas de perfuração rotativas dividem-se em sistemas, da qual apresentam-se abaixo,(THOMAS,2001):

- Sustentação de cargas - Esse sistema é constituído do mastro ou torre, da subestrutura e da base ou fundação. A carga corresponde ao peso da coluna de perfuração ou revestimento que está no poço é transferida par ao mastro ou torre, que, por sua vez, descarrega para a subestrutura e esta para a fundação ou base.

- Movimentação de cargas - Permite movimentar as colunas de perfuração, de revestimento e outros equipamentos. Os principais componentes do sistema são: guincho, bloco de coroamento, catarina, cabo de perfuração, gancho e elevador.

- Geração e transmissão de energia - É o sistema responsável pelo fornecimento de energia para as sondas, que é normalmente gerada por motores a diesel. Pode ser utilizado também o uso de energia elétrica de redes públicas, quando houver disponibilidade. 
- Rotação - Em sondas convencionais, a coluna de perfuração é girada pela mesa rotativa que está localizada na plataforma da sonda. Já em sondas equipadas com top drive a rotação é transmitida diretamente ao topo da coluna de perfuração por um motor aclopado a catarina. Existe ainda a possibilidade de perfurar com um motor de fundo, colocado logo acima da broca de perfuração.

- Circulação - É o sistema responsável por toda a circulação e tratamento de fluido de perfuração, onde passa desde a fase de injeção, retorno e tratamento.

- Segurança e monitoramento do poço - Constitui de equipamentos de segurança de cabeça de poço (ESCP) e de equipamentos complementares que possibilitam o fechamento e controle do poço. Podemos citar o BlowoutPreventet $(B O P)$, que é um conjunto de válvulas que permite fechar o poço. Já os manômetros, indicadores de pressão, torque, peso são os equipamentos necessários para o controle da perfuração de uma sonda.

- Subsuperfície (coluna de perfuração) - A coluna de perfuração é a responsável direta por todo o processo e consta dos seguintes componentes principais: comandos, tubos pesados e tubos de perfuração.

\section{ACIDENTES DE TRABALHO}

Em relação aos trabalhadores que lidam diretamente com o trabalho da sonda de perfuração, os mesmos podem sofrer acidentes durante o expediente, isso ocorre em funçãodas condições físicas do local de trabalho e também pela condição do processo de trabalho, técnicas impróprias e equipamentos estragados que são capazes de provocar lesões à integridade física do trabalhador, podendo causar morte, perda ou redução permanente ou temporária, da capacidade para o trabalho. Segundo Saliba e Pagano (2007) de acordo com o Conceito Legal - Lei no 8.213, de 24 de julho de 1991, alterado pelo Decreto no 611, de 21 de julho de 1992, "Acidente do trabalho" é:

- Aquele que acontece quando você está prestando serviços por ordem da empresa fora do local de trabalho;

- Aquele que acontece quando você estiver em viagem a serviço da empresa;

- Aquele que ocorre no trajeto entre a casa e o trabalho ou do trabalho para casa;

- Doenças profissionais (as doenças provocadas pelo tipo de trabalho. Ex. problemas de coluna);

- Doença do trabalho (as doenças causadas pelas condições do trabalho. Ex. dermatoses causadas por cal e cimento).

Originalmente, os primeiros teóricos reduziram a avaliação das causas de acidentes aos atos inseguros e condições inseguras. Essa teoria foi a base trazida pela pelo Governo brasileiro, na década de 1970, para formar emergencialmente profissionais para atuarem na área de prevenção de acidentes, uma vez que mais de um milhão de acidentes ocorriam por ano. Essa teoria foi denominada de Teoria do Dominó.

A teoria de Heinrich com atos inseguros e condições inseguras influenciou a segurança ocupacional e a análise de acidentes durante décadas. Essa teoria possui uma idéia simples, pois 
descreve os acidentes como uma sequência de eventos que pode ser visualizada e segue uma ordem específica. Essa teoria é a base para o Modelo Sequencial dos Acidentes, o qual descreve um acidente como uma sequência de dominós que caem por causa de um único evento iniciador.

\section{TEORIA DO DOMINÓ DE HEIRINCH}

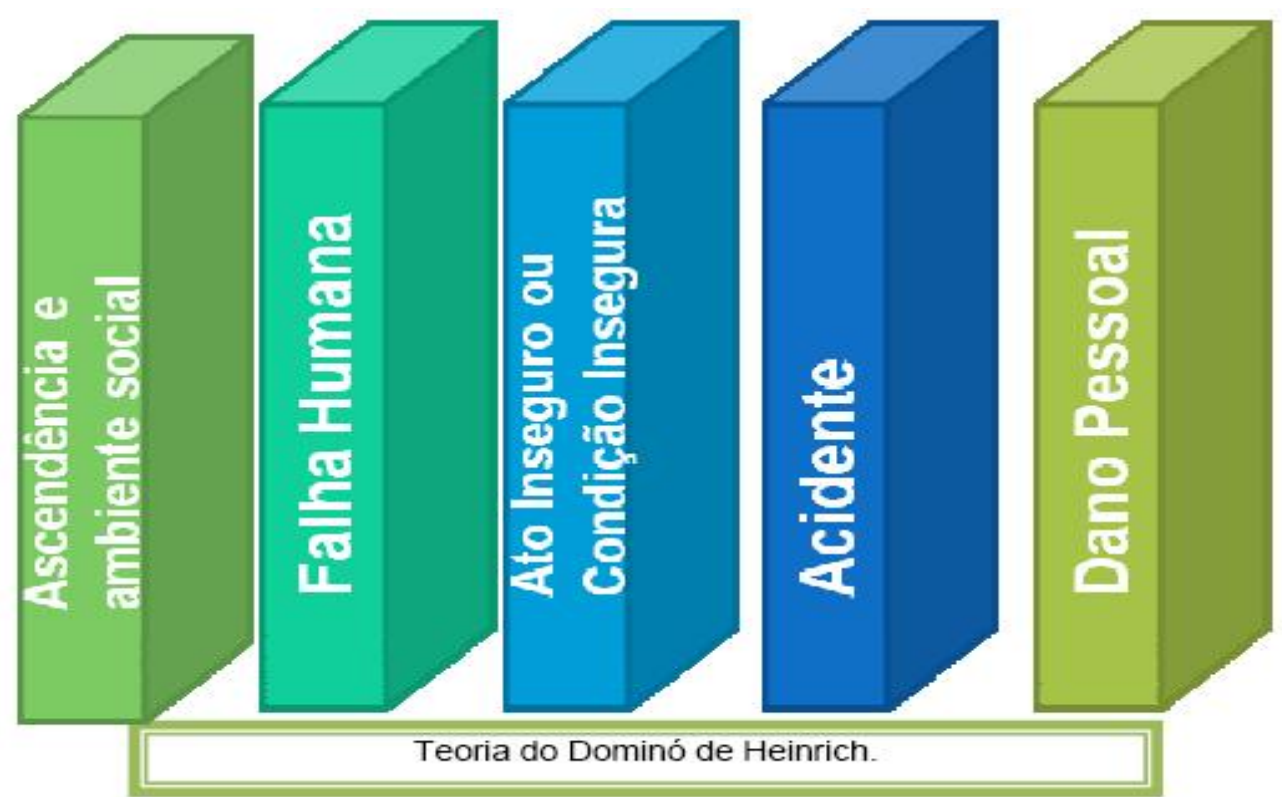

Figura 1- Teoria do Dominó de Heirinch. Fonte: HEIRINCH, H. W. Industrial accidentsprevention - 1959.

Heinrich postula cinco metafóricos dominós rotulados como causas de acidente: ambiente social e ascendência, falhas humanas, atos inseguros ou condições inseguras, acidentes e lesões ou danos pessoais.

A teoria afirma que os acidentes resultam de uma cadeia de eventos sequenciais, metaforicamente ajustados como uma linha de dominós. Quando um dos dominós cai, há uma ação em cadeia que derruba os demais. No entanto, se for eliminado um fator-chave, como uma condição insegura ou um ato inseguro, pode ocorrer uma ação que impede o desenrolar da reação em cadeia, evitando assim, o acidente.

Ambiente social e ascendência - $O$ primeiro evento da sequência trata da personalidade do trabalhador, ou seja, os indesejáveis traços da personalidade como a teimosia e a imprudência, podem ser transmitidos ao longo do tempo por herança ancestral, daí o termo ascendência.

Falhas humanas- Esse segundo evento também lida com traços de personalidade do trabalhador, onde o caráter inato ou falhas de personalidade, inaptidão entre o homem e a função, desconhecimento dos riscos da função, contribuem em um acidente. 
Condições inseguras - O terceiro evento trata diretamente das causas do acidentes. Como mencionado acima, esses fatores como situações que podem existir no ambiente, capazes de promover um acidente como, por exemplo, a falta de iluminação, ruídos em excesso, piso escorregadio.

Acidentes - O quarto evento é o acidente que é uma ação que pode ser evitada se observarmos as ações cometidas em sequência pelo trabalhador.

Lesões ou danos pessoais - O quinto e último evento apresenta os resultados dos acidentes, ou seja, os danos físicos.

Já o estudioso norte americano Frank Bird, nos anos de 1967 e 1968, analisou 297 companhias nos Estados Unidos da América, sendo envolvidas nessa análise 170.000 pessoas de 21 grupos diferentes de trabalho. Neste período, houve 1.753 .498 acidentes comunicados. (BENITE, 2004)

Com base nesses dados, Bird, criou a pirâmide que denominou "pirâmide de Frank Bird", onde chegou-se a conclusão que, para que aconteça um acidente que incapacite o trabalhador, anteriormente acontecerão 600 incidentes sem danos pessoais e/ou materiais.

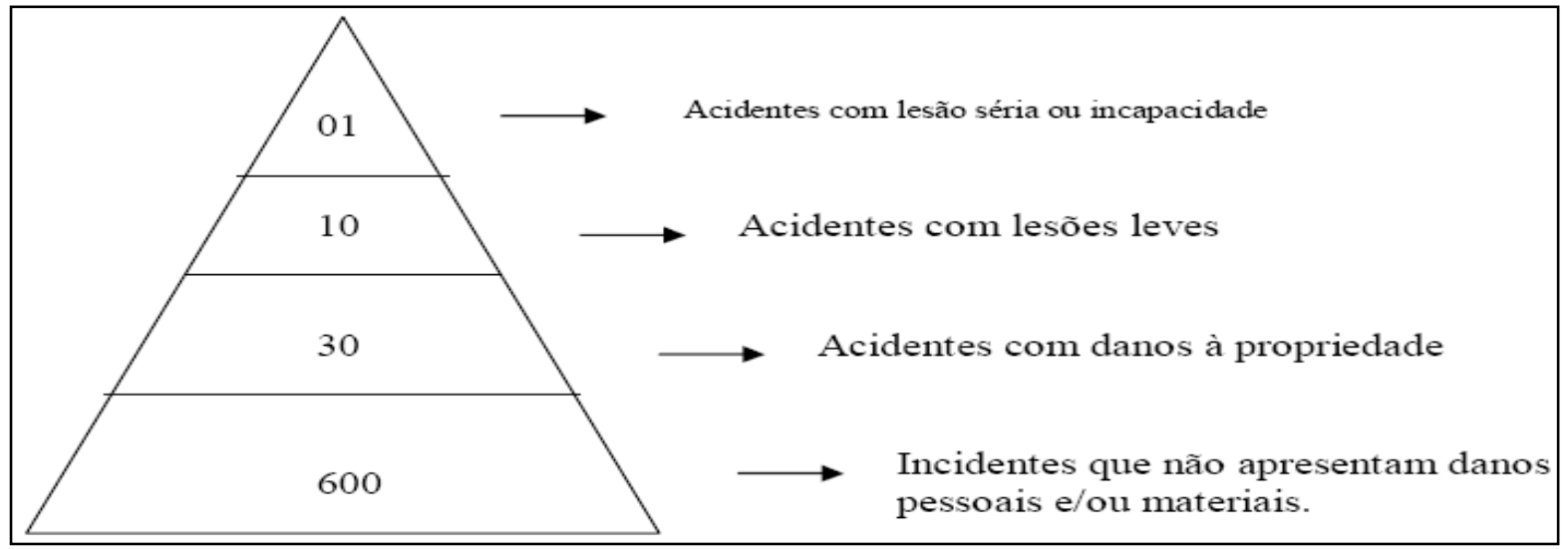

Figura 2: Pirâmide de Bird. Fonte: Henrique, 1982

Observa-se que na pirâmide de Bird, explicita que em cada 600 ocorrências de incidentes resultando ou não em danos materiais (quase acidente), gera 30 acidentes com danos à propriedade, destes 10 acidentes com lesões leves e 1 acidente com lesão séria, incapacidade ou óbito.

Com base nos seus estudos, Bird concluiu que, todos os esforços deveriam ser empreendidos para a base da pirâmide, ou seja, objetivando buscar sempre a reduzir a possibilidade de ocorrência dos "quase acidentes", minimizando os incidentes, é possível em uma escala proporcional reduzir os acidentes com lesões leves ou sérias. 
Os acidentes ocorrem no cotidiano e, de uma forma ou outra tem impactos praticamente a todos. Somente no ano de 2007, segundo a Fundacentro, órgão responsável pela pesquisa de segurança ocupacional no Brasil, ocorreram em todo o país 503.890 acidentes de trabalho. Isso quer dizer que o Brasil perde, por ano, o equivalente a 4\% do PIB por causa dos acidentes de trabalho.

A Fundacentro avalia que esses acidentes ocorrem devido às condições precárias de trabalho, do uso de máquinas obsoletas e de processos inadequados.

Segundo a Organização Internacional do Trabalho (OIT), é estimado que o mundo tenha 6.000 mortes de trabalhadores por dia devido a algum acidente ocupacional ou doenças do trabalho.

\section{PERIGOS E RISCOS}

Alguns trabalhos podem oferecer riscos de acidentes ou põe em perigo a vida do trabalhador, e em se tratandoespecificamente do trabalho com a sonda de perfuração essas ocorrências ainda podem ser maiores. Isso porque o processo de perfuração em uma sonda envolve muito perigos e há constantemente riscos de acidentes. De acordo com o anexo I item 4.20, da NR-4, do Ministério do Trabalho e Emprego, o grau de risco dessa atividade é 4. Essa norma gradua essas atividades de 1 a 4 . A natureza dessa atividade implica numa graduação alta, o que justifica cuidados especiais quanto aos riscos.

E o perigo é uma condição física ou química que tem o potencial para causar danos às pessoas, propriedades ou ao meio ambiente. As atividades da indústria petrolífera têm perigos associados aos tipos de trabalhos característicos de seus processos.

Dentre os perigos em uma sonda de perfuração de petróleo Onshore, pode citar: Explosão, incêndio, vazamento de gás inflamável e tóxico, vazamento de produtos químicos e inflamáveis.

Já os riscos é uma situação com potencial de consequências indesejáveis a vida humana, a saúde e ao meio ambiente. Os riscos associados aos processos correspondem à qualificação ou quantificação dos perigos correspondentes aos serviços ou produtos desses processos.

\section{RISCOS AMBIENTAIS}

Os riscos ambientais, como citados anteriormente podem ser causados por qualquer agente de natureza variável e quando presentes no ambiente de trabalho podem vir a causar danos à saúde do trabalhador por sua natureza, concentração, intensidade ou tempo de exposição. Entre os mesmos podemos identificar:

\section{Riscos físicos}

Originados de ações, situações de origem física ou energias que podem vir a provocar danos à saúde do trabalhador, podendo ser classificados como: 
- ruído- provocado pela agitação mecânica do ar através de um agente físico como uma máquina, ferramentas ou equipamentos. Sua medida é o decibel e o limite para 8 horas de trabalho é de 85 decibéis. Em uma sonda de perfuração esse limite é ultrapassado, por isso se faz necessário o uso de equipamentos de proteção individual.

- vibrações- decorrem da movimentação mecânica de máquinas, ferramentas e equipamentos. Essas vibrações são transmitidas ao trabalhador quando operando a fonte de vibração. Por se tratar de um processo mecânico, existe muita vibração em uma atividade de perfuração de poços de petróleo.

- pressões anormais- decorrentes de trabalhos onde a pressão é superior ou inferior a pressão atmosférica ao nível do mar.

- umidade - decorrente de atividades relacionadas com água ou líquidos.

- temperaturas extremas - as temperaturas extremas decorrem de atividades que consistem em mudar de uma temperatura alta para baixa ou vice-versa, por sua natureza.

- radiações - as radiações podem ser ionizantes e não ionizantes. O que determina é a frequência da onda. As radiações cujas frequências são maiores que o ultravioleta são chamadas de ionizantes, por possuírem capacidade de ionizar os átomos e permitirem alterações no DNA. As radiações cuja frequências são menores que o ultravioleta são chamadas de não-ionizantes e entre elas estão enquadradas as ondas de rádio, o micro-ondas e a radiação de luz.

\section{Riscos químicos}

Originados de produtos químicos, substâncias ou compostos que podem penetrar no organismo pela via respiratória, ou que, pela natureza da atividade de exposição, venham a ter contato ou ser absorvidos pelo organismo através da pele ou por ingestão e que possam vir a provocar danos à saúde do trabalhador. São eles:

- poeiras- são materiais em partículas finas em suspensão no ar oriundos de diversas atividades, como demolição, britagem, transporte de grãos etc.

- fumos - são metais fundidos que ao entrarem em contato com o ar voltam ao estado sólido, mas em formato microscópicos.

- névoas- são produtos químicos em forma de gotas minúsculas que podem ser produzidas por aspersão ou por reações químicas/fotoquímicas. O SMOG é um exemplo de névoa fotoquímica.

- gases- é um dos estados da matéria onde podemos encontrar uma série de produtos químicos de uso industrial e doméstico. Possuem diversas características de acordo com sua composição.

- vapores- são substâncias químicas que estão passando do estado sólido para o estado gasoso. 


\section{Riscos biológicos}

São riscos originados de microorganismos que podem vir a provocar danos à saúde do trabalhador. Há uma série de atividades humanas relacionadas à contaminação biológica, como atividades na área de saúde, produção de alimentos, frigoríficos, produção animal e outras como a arqueologia. Os principais riscos biológicos são:

-bactérias- são micro-organismos unicelulares extremamente simples sem núcleo organizado. Podem ou não causar doenças.

- fungos- constituem um reino biológico próprio. São compostos de filamentos chamados de hifa, cujo conjunto em um mesmo organismo é chamado de micélio. Os fungos aparecem em materiais orgânicos e são usados em uma quantidade de processos industriais principalmente na fermentação.

- protozoários- são organismos unicelulares com núcleos organizados que podem ou não provocar doenças.

- vírus- não se enquadram facilmente em qualquer das categorias de classificação dos seres vivos. Isso ocorre devido a como classificá-los, pelo fato de haver dúvidas sobre se devem o não ser considerados seres vivos. Os vírus possuem uma "vida" completamente diferente das células. Os vírus não fazem metabolismo, apenas se reproduzem e somente em células que tenha afinidades, ou seja, os vírus só atacam células específicas

\section{Riscos ergonômicos}

Decorrentes da adaptação do homem ao trabalho. A ergonomia é a disciplina científica que se preocupa com design e desenho de máquinas, equipamentos, ferramentas e dispositivos; de acordo com as necessidades humanas. (SANTOS, 1997)

Segundo a Norma Regulamentadora NR-17, do Ministério do Trabalho e Emprego, a ergonomia visa a estabelecer parâmetros que permitam a adaptação das condições de trabalho às características psicofisiológicas dos trabalhadores, de modo a proporcionar um máximo de conforto, segurança e desempenho eficiente.

Essa disciplina aplica a teoria, princípios, dados e métodos para projetar, com a finalidade de otimizar o bem estar humano, sua adaptação ao trabalho e o desempenho global do sistema homem $\mathrm{x}$ dispositivo ou homem $x$ tarefa.

Existem cinco aspectos da ergonomia que devem ser levados em consideração na elaboração ou mudança de um projeto: segurança, conforto, facilidade de uso, produtividade/desempenho e estética. 
Em uma sonda de perfuração, os itens: Conforto, facilidade de uso, e estética estão em segundo plano. Pois como essa atividade é bastante onerosa, as empresas buscam atender os padrões de segurança exigidos buscando a produtividade e desempenho.

\section{PROGRAMA DE PREVENÇÃO DE RISCOS AMBIENTAIS - PPRA}

O programa de prevenção de riscos ambientais, segundo a Norma Regulamentadora NR 9, do Ministério do Trabalho e Emprego, é parte integrante do conjunto mais amplo das iniciativas da empresa no campo da preservação da saúde e da integridade dos trabalhadores. Esta Norma Regulamentadora estabelece a obrigatoriedade da elaboração e implantação, por parte de todos os empregadores e instituições que admitam trabalhadores como empregados, do Programa de Prevenção de Riscos Ambientais - PPRA, visando à preservação da saúde e da integridade dos trabalhadores, através da antecipação, reconhecimento, avaliação e conseqüente controle da ocorrência de riscos ambientais existentes ou que venham a existir no ambiente de trabalho, tendo em consideração a proteção do meio ambiente e dos recursos naturais.

As ações do PPRA devem ser desenvolvidas no âmbito de cada estabelecimento da empresa, sob a responsabilidade do empregador, com a participação dos trabalhadores, sendo sua abrangência e profundidade dependentes das características dos riscos e das necessidades de controle.

A NR-9 considera os riscos ambientais, os agentes físicos, químicos e biológicos existentes nos ambientes de trabalho que, em função de sua natureza, concentração ou intensidade e tempo de exposição, são capazes de causar danos à saúde do trabalhador.

\section{MAPAS DE RISCOS}

É uma representação ilustrada dos pontos de riscos encontrados em cada setor, tornando-se uma maneira fácil e rápida de representar os riscos de acidentes de trabalho.

O mapeamento de risco surgiu na Itália entre o final da década de 60 e início da década de 70, através do movimento sindical, com origem na Federazione deiLavoratoriMetalmeccanici(FLM) que, na época, desenvolveu um modelo próprio de atuação na investigação e controle das condições de trabalho pelos trabalhadores, o conhecido "Modelo Operário Italiano".

Tal modelo tinha como premissas a formação de grupos homogêneos, a experiência ou subjetividade operária, a validação consensual e a não-delegação, possibilitando assim a participação dos trabalhadores nas ações de planejamento e controle da saúde nos locais de trabalho, não delegando tais funções aos técnicos e valorizando a experiência e o conhecimento operário existente.

Para que o ambiente de trabalho fique livre da nocividade que sempre o acompanha, é necessário que as descobertas científicas neste campo sejam socializadas, isto é, trazidas ao conhecimento dos trabalhadores de uma 
forma eficaz; é necessário que a classe operária se aproprie delas e se posicione como protagonista na luta contra as doenças, as incapacidades e as mortes no trabalho. Somente uma real posição de hegemonia da classe operária diante dos problemas da nocividade pode garantir as transformações que podem e devem determinar um ambiente de trabalho adequado para o homem. Somente a luta, com uma ação sindical conduzida com precisos objetivos reivindicatórios, com a conquista de um poder real dos trabalhadores e do sindicato, é possível impor as modificações, sejam tecnológicos, técnicas ou normativas, que possam anular ou reduzir ao mínimo os riscos a que o trabalhador está exposto no local de trabalho. (Oddoneet al., 1986: 17)

Segundo o autor Oddoneet al., essa metodologia teve um importante papel no processo da Reforma Sanitária Italiana (Lei 833 de 23/09/78 que instituiu o Serviço Sanitário Nacional) que criou condições para construção de um sistema participativo e com auto-regulação na eliminação dos riscos, prevendo em seu artigo 20 os mapas de risco.

O Mapa de Risco se difundiu por todo o mundo, chegando ao Brasil no início da década de 80, porém há duas versões quanto à sua introdução no Brasil. A primeira, atribui tal feito às áreas sindical e acadêmica, através de David Capistrano, Mário Gaawryzewski, Hélio Baís Martins Filho e do Departamento Intersindical de Estudos em Saúde e Ambiente de Trabalho (Diesat).

A outra versão atribui à Fundação Jorge Duplat Figueiredo de Segurança e Medicina do Trabalho (Fundacentro) a difusão do mapa de risco no país. Segundo o Engenheiro Mário Abrahão (1993, p.22):

Técnicos da Fundacentro de Minas Gerais foram designados para estudar o método de trabalho e acompanhar os resultados. Após um longo acompanhamento e a constatação dos resultados positivos, eles começaram como agentes multiplicadores a ensinar esta técnica por todo o País. Em São Paulo, graças aos esforços conjuntos da Fundacentro São Paulo, Delegacia Regional do Trabalho de Osasco e Sindicato dos Metalúrgicos de Osasco, que em 1982 patrocinaram dois cursos com os técnicos de Minas Gerais, preparando 40 novos instrutores de diversos ramos de atividades, aproximadamente 200 empresas já estão aplicando esta técnica com resultados positivos.

O Mapa de Risco foi criado através da Portaria n 05 em 17/08/92 do Departamento Nacional de Segurança e Saúde do Trabalhador do Ministério do Trabalho e Emprego, tratando da obrigatoriedade, por parte de todas as empresas, da "representação gráfica dos riscos existentes nos diversos locais de trabalho", e faz parte da NR-09. O mesmo tem como objetivos: 
reunir as informações necessárias para estabelecer o diagnóstico da situação de segurança e saúde no trabalho na empresa;

possibilitar, durante a sua elaboração, a troca e divulgação de informações entre os trabalhadores, bem como estimular sua participação nas atividades de prevenção.

A Portaria n. 25 da SST de 29/12/94 estabelece as diretrizes básicas para a elaboração dos mapas de riscos que são:

a) Indicar os pontos de riscos;

b) Tornar possível a visualização do ambiente, do ponto de vista dos riscos encontrados por todos os trabalhadores do local, pelo Serviço de segurança e Medicina do Trabalho e pela administração da empresa.

c) Facilitar a discussão e a escolha das prioridades a serem trabalhadas pela CIPA.

d) Após o exame desse mapa, pode-se estudar as medidas necessárias ao saneamento do ambiente e elaborar o Plano de Trabalho, para se obter a implementação de medidas corretivas.

Os mapas de riscos são criados em uma planta, e os riscos são identificados por cores e círculos conforme figura abaixo:

\section{OS RISCOS AMBIENTAIS E SUAS CORES IDENTIFICADORAS.}

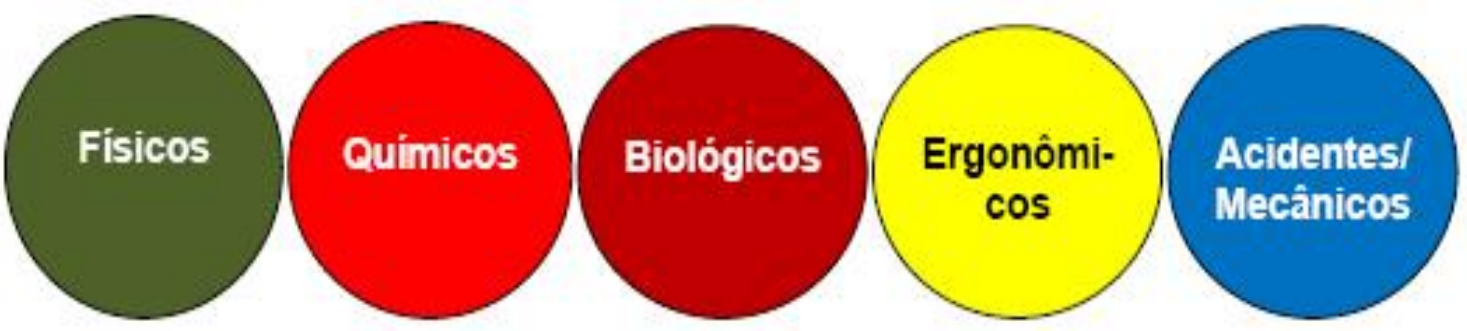

Figura 3-Os riscos ambientais e suas cores identificadoras. Fonte: BRASIL, 1992.

A intensidade do risco avaliado é mostrada por tamanhos variados dos círculos em proporção definida, conforme você pode observar a seguir: 


\section{SIMBOLOGIA DAS CORES}

\begin{tabular}{|c|c|c|}
\hline \multirow{3}{*}{$\begin{array}{l}\text { Simbologia das Cores } \\
\text { No mapa de risco, os riscos sẫo } \\
\text { representadoes e indicados por } \\
\text { circulos coloridos de três tamanhos } \\
\text { diferentes, a saber: }\end{array}$} & Risco Químico Leve & Risco Mecânico Leve \\
\hline & Risco Químico Médio & $\begin{array}{l}\text { Risco Mecânico } \\
\text { Médio }\end{array}$ \\
\hline & Bisco Ouímico Flavado & Risco Mecânico \\
\hline Risco Biológico Leve & Risco Ergonômico Leve & Risco Físico Leve \\
\hline Risco Biológico Médio & $\begin{array}{l}\text { Risco Ergonômico } \\
\text { Médio }\end{array}$ & Risco Físico Médio \\
\hline Risco Biológico Elevado & $\begin{array}{l}\text { Risco Ergonômico } \\
\text { Elevado }\end{array}$ & Risco Físico Elevado \\
\hline
\end{tabular}

Quadro 1- simbologia das cores de um mapa de risco. Fonte: BRASIL, 1992.

Em cada setor de trabalho deve ser indicado o risco ambiental que o trabalhador está exposto como mostra o quadro acima, no entanto não deve o trabalhador somente esperar que sua empresa faça essa identificação, é importante que eles busquem se organizar e exigir da empresa essas identificações ou até se preciso for, mobilizar o sindicato de trabalhadores para exigirem seus direitos.

\section{ANÁLISE DE RESULTADOS}

Tendo em vista os riscos de acidentes possíveis de se realizar em uma sonda de perfuração o trabalho teve como objetivo desenvolver um mapeamento dos tipos de riscos ambientais (físicos, químicos, mecânicos, ergonômicos, biológicos) de uma sonda de perfuração de petróleo (Onshore), tendo como base o programa de Segurança, Meio Ambiente e Saúde (SMS) visando propor ações que minimize os acidentes com riscos ambientais na UN-RN/CE- MOSSORÓ/RN.

Para se obter os dados apresentados foi necessário deslocar-se até a cidade de Mossoró e contactar com o supervisor de SMS o Sr. Franklin Liberato Rodrigues de Souza da Petrobrás - UNRN/CE- Mossoró, do qual, foi muito solícito como anfitriã e fazer uma entrevista com o mesmo. Todas as informações solicitadas foram obtidas, algumas durante a entrevista e outras aguardou-se retorno.

Deste modo, apresenta-se o resultado do trabalho de pesquisa desenvolvido na seguinte seqüência: 
1-- O mapeamento dos tipos de riscos ambientais de uma sonda de perfuração, construído a partir das informações obtidas na pesquisa sobre os lugares de mais riscos ambientais em uma sonda de perfuração.

20- Os acidentes ocorridos na UN-RN/CE- Mossoró no período de janeiro a agosto de 2010, analisados por: Acidentes por operação, acidentes por turno, acidentes por partes do corpo atingidas e acidentes por experiência.

3-- Análise dos acidentes ocorridos comparando-os com os lugares ocorridos e o setor que mais está exposto a acidente ambiental na sonda de perfuração.

\section{0- MAPEAMENTOS DOS TIPOS DE RISCOS AMBIENTAIS DE UMA SONDA DE PERFURAÇÃO}

A Torre ou Mastro é uma estrutura de aço especial, de forma piramidal, serve para promover um espaço vertical livre acima da plataforma de trabalho para permitir a execução de manobras durante o processo de perfuração de um poço, sendo constituída deum grande número de peças. (THOMAS, 2001)

Os riscos identificados em uma torre ou mastro de uma sonda de perfuração sejam físicos, químicos, mecânicos e ergonômicos são muito elevados. Além de haver uma intensa movimentação de cargas (cabos de aço, colunas de perfuração/produção) o torrista fica no alto da torre acoplando e desacoplando as colunas.

Já a Subestruturaé constituída de vigas de aço especial montadas sobre a fundação ou base da sonda, de modo a criar um espaço de trabalho sob a plataforma, onde são instalados os equipamentos de segurança do poço. Suas fundações ou bases são estruturas rígidas construídas em concreto, aço ou madeira que, apoiadas sobre o solo resistente, suportam com segurança as deflexões, vibrações e deslocamentos provocados pela sonda. É o local da sonda onde existe o maior número de pessoas trabalhando ao mesmo tempo. É onde os plataformistas e o sondador estão. Praticamente só não existe o risco biológico, os outros são de graus elevados.

O equipamento que transmite rotação a coluna de perfuração e suporta todo o peso da coluna de perfuração é a mesa rotativa, em alguns modelos mais modernos de sonda não existe mais esse equipamento. Os riscos são altos nessa área, pois a muitos equipamentos mecânicos em funcionamento (elevadores, chaves flutuantes) há também intenso barulho e vibrações excessivos, além de perigo de explosões (blowout) devido a bolsões de gás atingidos pela coluna de perfuração.

Enquanto que a Bomba de Lama é responsável pela circulação do fluído de perfuração. Alto ruído, vibrações intensas, riscos de contaminação do fluído oriundo das formações geológicas perfuradas, riscos de mecânicos por existirem muitas partes móveis. 
O Gerador de energia fornece a energia em uma sonda, normalmente os geradores são movidos a óleo diesel. Extremo barulho, altas temperaturas, risco de choque elétrico (600 volts), partes móveis.

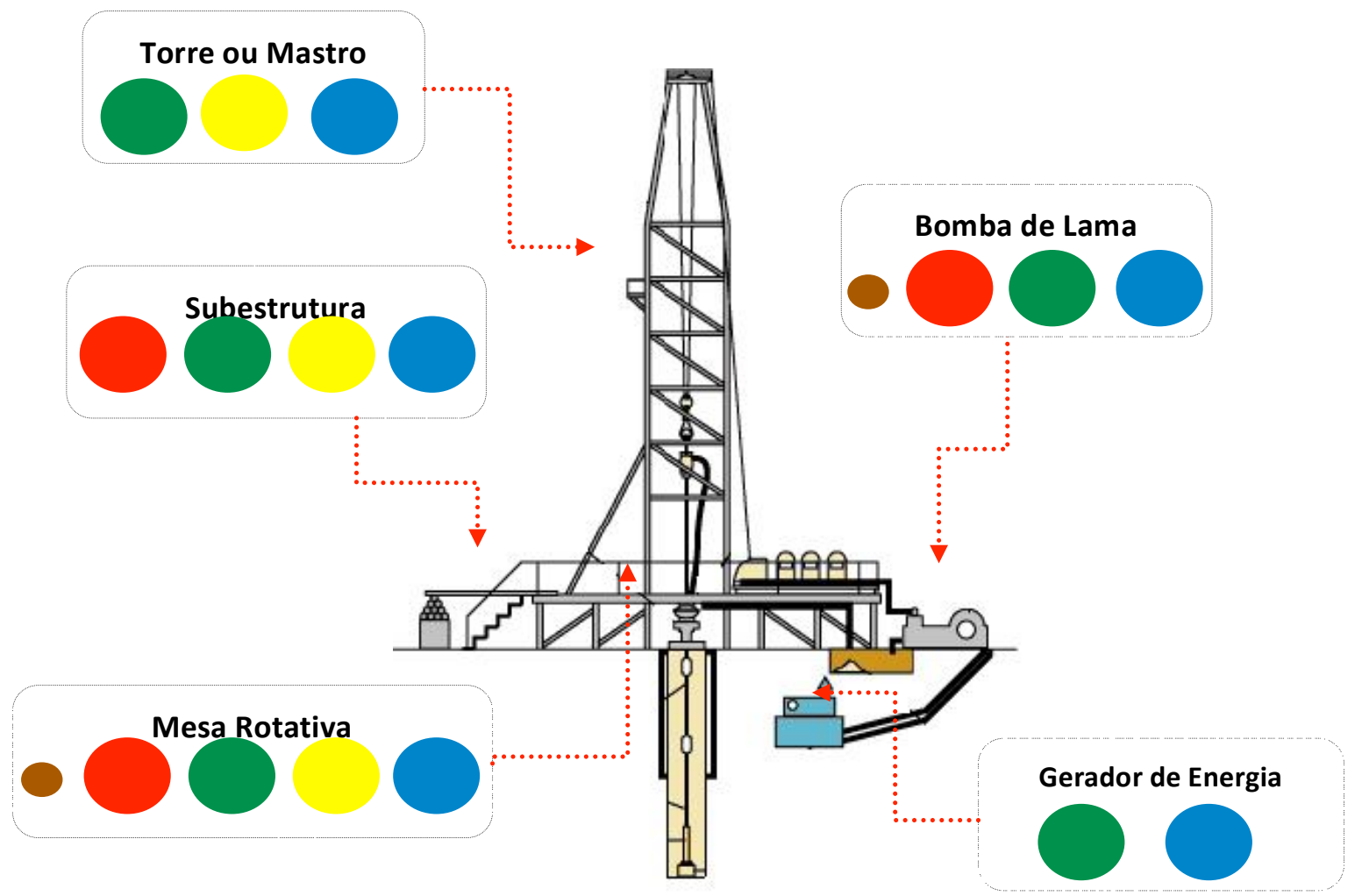

Figura 4-Mapa de riscos de uma sonda de perfuração Onshore. Fonte: Elaborado pelo próprio autor

Percebe-se que a equipe que mais teve acidente foi a de Desmontagem / Transporte / Montagem (DTM) da sonda, esses operários têm acesso em toda a extensão na torre da sonda, o que possibilita uma exposição maior aos riscos ambientais físicos, químicos, biológico, mecânico e ergonômico mais elevados.

Esses acidentes ocorreram na sua maioria durante o dia tendo os membros superiores mais atingidos e os operários envolvidos nestes acidentes já possuem em média de 1 a 3 anos de experiência neste tipo de operação.

O que se permite perceber, que, é preciso intensificar os cuidados com acidentes desta turma em seu turno, já que se identificou a necessidade deste grupo ficar mais atentos nas atividades desenvolvidos devido o índice de acidentes ocorridos durante o primeiro semestre de 2010.

Em relação a esse papel, compete ao trabalho do Técnico de Segurança de Trabalho desta empresa, em intensificar a atenção constante desses trabalhadores ao desempenhar seus serviços, tendo em vista, que um acidente pode acontecer inesperadamente. Desenvolver possíveis reuniões, palestras, vídeos que relatem acidentes e os meios simples, porém, precisos para evitá-los. 
É preciso ressaltar então, que é de suma importância seguir as Normas de SMS, para que os trabalhadores possam compreender a magnitude de riscos que os mesmos correm e que com um ato simples de manter um capacete na cabeça pode vir salvar sua vida, pois são riscos eminentes.

Ainda mais, com tantos meios de se evitar um grave acidente, do qual, apenas necessita da conscientização dos mesmos. O que permite a sugestão de se ter exposto no ambiente de trabalho esse mapeamento dos riscos ambientais em uma sonda para que o operário possa se manter cauteloso em cada atividade que o mesmo desempenhar no seu setor.

\section{CONSIDERAÇÕES FINAIS}

Devido a esse alto grau de risco que a atividade petrolífera está inserida, o conhecimento sobre essa problemática torna-se relevante, pois o estudo sobre essa variável tem como objetivo identificar os riscos ambientais aos quais estão submetidos os profissionais que trabalham em uma sonda de perfuração.

Tendo em vista que estes riscos podem acarretar na vida destes profissionais, concluo que o conhecimento sobre esse assunto torna-se relevante, no sentido de enquanto Gestor Ambiental poder contribuir para minimizar os riscos que eles estão submetidos no desenvolvimento de suas atividades.

Durante o processo de pesquisa deste trabalho, foi possível ir identificando que o risco de acidentes em uma sonda de perfuração é elevado e que existem determinados lugares na mesma que o operário ao desenvolver seu trabalho se expõe a um índice maior dos riscos ambientais. O ponto auge da pesquisa se deu com a possibilidade de através da construção do mapeamento de riscos ambientais de uma sonda comparar com os dados obtidos junto à Petrobrás UN-RN/CE- MOSSORÓ/RN, dos acidentes que ocorreram durante o primeiro semestre de 2010, contribuindo com o aprofundamento e conclusão dessa pesquisa.

Assim, o trabalho desenvolvido, destacou a importância dos profissionais que trabalham em uma sonda de perfuração ter conhecimento mais detalhado dos riscos que os mesmos correm durante o seu trabalho. $O$ que permite ressaltar que o objetivo principal do trabalho de construir um mapeamento de risco de uma sonda de perfuração tendo como base o programa de Segurança, Meio Ambiente e Saúde (SMS) visando propor ações que minimize os acidentes com riscos ambientais na UN-RN/CE- MOSSORÓ/RN, foi alcançado, pois, os riscos foram identificados, alertando o que se pode fazer para evitar acidentes utilizando os equipamentos adequados ao uso coletivo e individual. Contribuindo de forma significativa a UN-RN/CE- MOSSORÓ/RN o trabalho necessário a se desenvolver com a equipe que mais se expôs a acidentes, além, é claro, de como todas as outras equipes.

Poder também oferecer a um setor tão importante, como a extração de petróleo, que cresce significamente, a oportunidade de continuar desenvolvendo seu trabalho de forma mais segura, me faz acreditar que a pesquisa nos abre horizontes antes não alcançados. 
Em relação a mim, acadêmico em Gestão Ambiental, fica de grande valia o trabalho concluído, tendo em vista, o crescimento profissional e pessoal que me proporcionou e a aprendizagem que não se pode tirar e sim sempre acrescentar.

\section{REFERÊNCIAS}

1. ABRHÃO, M. J. 1993. Mapeamento de risco CIPA, 159: 22-27.

2. ALVES, A. J. O planejamento de pesquisas qualitativas em educação. Cadernos de Pesquisa, São Paulo, v. 77, p. 53-61, maio, 1991.

3. APPENZELLER, Tim, Petróleo perto do fim? In: Revista Nacional Geographic Brasil, ano 5 no 50. São Paulo- SP, junho. Pag. 110 - 133. 2004.

4. BRASIL, 1992. Portaria no 3214 de 08/06/78. In: Normas Regulamentares em Segurança e Medicina do Trabalho (Ministério de Trabalho), São Paulo; Atlas.

5. BRASIL. Ministério do Trabalho e Emprego. Caminhos da análise de acidentes do trabalho. Brasília - DF, 2003.

6. 1992. Portaria no 05 de 18/08/92. Dispõe sobre modificações na NR-9 (Riscos Ambientais) e a obrigatoriedade de elaboração de Mapas de Riscos pelas empresas que possuam CIPAs. Brasília: Diário Oficial da União, 20/08/92.

7. - Norma Regulamentadora NR 17, Ministério do trabalho e Emprego MTE Ergonomia - Portaria GM n.o 3.214, de 08 de junho de 1978.

8. Norma Regulamentadora NR 4, Ministério do trabalho e Emprego MTE - Serviços especializados em engenharia de segurança e em medicina do trabalho - Portaria GM n.ㅇ 3.214, de 08 de junho de 1978.

9. - Norma Regulamentadora NR 6, Ministério do trabalho e Emprego MTE Equipamento de proteção individual - EPI - Portaria GM n. 3.214, de 08 de junho de 1978.

10. Normas regulamentadoras. Ministério do Trabalho e Emprego. Disponível em: http://www.mte.gov.br/legislacao/normas_regulamentadoras/default.asp>. $\quad<$ acesso em: 25 fev. 2010.> 
11. BENITE, Anderson Glauco. Sistema de Gestão de segurança e Saúde no Trabalho: Conceito e Diretrizes para a Implementação da Norma OHSAS 18.001 e Guia ILO OSH da OIT. 1ed. São Paulo, SP: O Nome da Rosa, 2004.

12. CANELAS, André L. S.: Investimentos em Exploração e Produção Após a Abertura da Indústria Petrolífera no Brasil: Impactos Econômicos. 2004. 87 f. Monografia (Bacharelado em Ciências Econômicas) Instituto de Economia, Universidade Federal do Rio de Janeiro, Rio de Janeiro, 2004.

13. FONSECA, Alan Wescley Barbalho, SILVA, Maria da Conceição da Paz. A exploração do petróleo e a dinâmica territorial no município de Mossoró.2008. Monografia (Bacharelado em Geografia) Universidade Federal do Rio Grande do Norte. Rio Grande do Norte, 2008.

14. FREITAS, N. B. B., 1992. Mapa de risco ambiental agora é lei federal. Trabalho e Saúde, 33: 10-11.

15. 1992. Da Saúde Ocupacional à Saúde do Trabalhador. São Paulo: Diesat. (Mimeo.)

16. GOLDENBERG, M. A arte de pesquisar: como fazer pesquisa qualitativa em Ciências Sociais. Rio de Janeiro: Record, 1999.

17. HENRIQUE, Hernán. Prevenção e Perdas: Engenharia de Prevenção de Perdas. São Paulo: ABPA. 1982.

18. HEIRINCH, H. W. Industrial accidents prevention. A scientific approach. 4. ed. New York: Mc Graw-Hill, 1959.

19. KUCHENBECKER, R., 1992. O modelo operário italiano $\mathbf{3 0}$ anos depois. Saúde em Debate, 36: 48-50.

20. NEVES, J. L.Pesquisa qualitativa: características, usos e possibilidades. Cadernos de Pesquisas em Administração, v. 1, n.3, 2o sem., 1996.

21. LAROUSSE, DICIONÁRIO da Língua Portuguesa.São Paulo - SP: Ed. Nova Cultura, 1992.

22. LEMOS, Francisco Antônio Castro. Tratamento e destinação final de resíduos de fluidos de perfuração de poços de petróleo. 1997. 79 f. Monografia (Especialização em Gerenciamento Ambiental) - Universidade Católica do Salvador, Salvador, 1997. 
23. LIMA, Heitor R. P. Fundamentos de Perfuração. Apostila do curso de formação de engenheiros de petróleo da Petrobras, Centro de Desenvolvimento de Recursos Humanos Norte-Nordeste, Salvador: 2001.

24. ODDONE, I.; MARRI, G.; GLORIA, S.; BRIANTE, G.; CHIATTELLA, M. \& RE, A., 1986. Ambiente de Trabalho: A Luta dos Trabalhadores pela Saúde.São Paulo: Hucitec.

25. PATTON, M. Qualitative research and evaluation methods. Londres, Thousand Oaks : Sage Publications, 2002.

26. SALIBA, Tuffi Messias; PAGANO, Sofia C. Reis Pagano. (Org.). Legislação de segurança, acidente do trabalho e saúde do trabalhador. 4. ed. São Paulo: LTr, 2007.

27. SANTOS, N. \& FIALHO, F. A. P., Manual de Análise Ergonômica no Trabalho. Curitiba: Gênesis Editora, 2 a Ed., 1997.

28. THOMAZ, José. Fundamentos da engenharia de petróleo. 2a Ed. Rio de Janeiro: Interciência: PETROBRAS, 2001, p.55-93 